\title{
DISINFECTION OF ANAESTHESIA EQUIPMENT BY A MECHANIZED PASTEURIZATION METHOD
}

\author{
Douglas B. Craig, S.A. Cowan, W. Forsyth, and Shirley E. Parker
}

IT IS NOW WELL ACCEPTED that contaminated anaesthetic breathing circuits can be the source of fatal nosocomial, or hospital acquired, infections. While common sense suggests that this would be true, strong supportive evidence has been provided, through the use of bacteriophage typing, in the investigation of two epidemics of Pseudomonas aeruginosa infections following surgery. ${ }^{1,2}$ Attention has now turned from confirmation of the hazard to the application of appropriate solutions. The use of ethylene oxide sterilization ${ }^{3}$ and/or the use of disposable equipment ${ }^{4}$ provides an effective solution of this problem. However, in many hospitals, including our own, ethylene oxide facilities are not large enough to accommodate the volume of anaesthetic equipment which must be processed. In addition, there has been reluctance to switch entirely to disposables, based on concerns for cost, quality, disposal and, more recently, availability. Other solutions are clearly required.

We utilize a simple method to mechanically process detachable components of anaesthetic breathing circuits. Equipment is washed in a standard automatic clothes-washing machine supplied with hot water at about $170^{\circ} \mathrm{F}\left(76.5^{\circ} \mathrm{C}\right)$. Disinfection is produced by "pasteurization", in which exposure to $75^{\circ} \mathrm{C}\left(167^{\circ} \mathrm{F}\right)$, water for at least 10 minutes will kill all vegetative organisms, but not bacterial spores. The use of pasteurization ${ }^{5,6}$ and of domestic automatic dishwashers ${ }^{7,8}$ has previously been reported for disinfection of inhalation therapy and anaesthetic equipment. This paper describes the current use of an established method, and examines its bacteriological efficacy. The two essential features of this system are water and electricity, both in plentiful supply in Canada.

\section{METHOD}

An automatic clothes-washing machine is supplied with water at $170^{\circ} \mathrm{F}$. Water from the hospital hot-water system at about $145^{\circ} \mathrm{F}$ is heated to $170^{\circ} \mathrm{F}$ in an industrial water heater. Dirty equipment is placed in the tub and goes through a 10-minute wash cycle, followed by a five-minute rinse cycle. Because of added filling and emptying time, the total exposure time of the equipment to the hot

Presented at the Annual Meeting, Canadian Anaesthetists' Society, St. John's, Newfoundland, 1974.

Departments of Anaesthesia and Microbiology, University of Manitoba, and Health Sciences Centre, Winnipeg, Manitoba. 
water approximates 20 minutes. The fall in temperature during the wash and rinse cycles is less than $5^{\circ} \mathrm{F}$. Nothing other than hot water is added to the washing machine, exoept a commercial protein dissolving soap, Lusan. Following the spin cycle, the moist equipment is removed from the washer and is hung to dry in an $\mathrm{X}$-ray film dryer. Warm air at about $130^{\circ} \mathrm{F}$ is circulated through this cabinet. Complete drying takes place in approximately 45 minutes. This system has now been in satisfactory use in our hospital for the past three years.

Equipment processed completely in this system includes corrugated rubber breathing tubes, breathing bags, and mask connectors. Oral and nasal airways and tracheal tubes are processed first in this system and then, following drying, are individually packaged and sterilized using ethylene oxide.

We examined the effectiveness of disinfection produced by this pasteurization process in two ways. Spot sampling of corrugated rubber breathing tubes at the end of the rinse cycle was done 44 times on six separate occasions. None showed evidence of contamination. We were reluctant to accept this evidence as absolute confirmation of the adequacy of the pasteurization system, and so developed a more challenging test of its bacteriological efficacy. This involved artificial contamination with four test organisms. The organisms used were Pseudomonas aeruginosa (pyocine type 3), Klebsiella pneumoniae (capsular type 3), earlier recovered from contaminated anaesthetic apparatus, as well as Staphylococcus aureus (Bacteriophage type 55/71), and Streptococcus faecalis (group D) which had been recovered from hospital clinical specimens. Streptococcus faecalis was chosen because of its known heat resistance.

The test organisms were held in storage medium at $4^{\circ} \mathrm{C}$, then cultured for 18 hours at $37^{\circ} \mathrm{C}$ in $100 \mathrm{ml}$ of Trypticase Soy Broth. Anaesthetic rubber breathing tubes which had been sterilized by autoclaving were inoculated by rinsing the cultures back and forth through them 25 times. The tubes were then hung to drain and were held overnight at room temperature. Only one organism was tested at any one time. In each test, nine tubes were contaminated, six being processed through the washer and dryer, and three retained unprocessed as controls. Three of the processed tubes were cultured following the washing process, and three following the drying. The three control tubes were sampled prior to processing and again at the same times that the processed tubes were being sampled. Sampling consisted of rinsing of $100 \mathrm{ml}$ of sterile normal saline 25 times through the tubes with recovery of the rinse fluid and culture in Trypticase Soy Agar, using various dilutions of the recovered fluid.

\section{Results}

Cultures of the control tubes always yielded growth in excess of $10^{8}$ organisms per $\mathrm{ml}$. This indicates massive contamination, well beyond what would be encountered in clinical practice.

The table summarizes the results of the cultures done on the processed breathing tubes contaminated with the four test organisms. The system was totally effective against the Pseudomonas and Streptococcus. Residual counts in 1 of 12 tubes contaminated with Klebsiella and in 4 of 24 containing Staphylococcus must be 
TABLE

Number of Tubes Found to be Contaminated with Test Organisms and with Other Organisms, when Cultured Following Washing and Following Drying

\begin{tabular}{|c|c|c|c|c|c|}
\hline \multirow[b]{3}{*}{ Test Organism } & \multirow{3}{*}{$\begin{array}{c}\text { Number of } \\
\text { Tubes } \\
\text { Tested }\end{array}$} & \multicolumn{4}{|c|}{ Number of Contaminated Tubes } \\
\hline & & \multicolumn{2}{|c|}{ Test Organism } & \multicolumn{2}{|c|}{ Other Organisms } \\
\hline & & $>$ Wash & $>$ Dry & $>$ Wash & $>$ Dry \\
\hline Pseudomonas & 48 & 0 & 0 & 8 & 4 \\
\hline Klebsiella & 12 & 0 & $1^{*}$ & 1 & 2 \\
\hline Staphylococcus & 24 & $4^{*}$ & $3 *$ & 2 & 1 \\
\hline Streptococcus & 12 & 0 & 0 & 0 & 2 \\
\hline
\end{tabular}

*Recovery Rate $<1$ Organism $/ 40 \mathrm{ml}$.

considered a partial failure of the system. It is important to recall, however, that all of the clinically contaminated tubes sampled in the earlier study were sterile following processing. In addition, the degree of contamination in this second phase of the study was massive, in excess of $10^{8}$ organisms per ml, while following processing the recovery rate was less than 1 organism per $40 \mathrm{ml}$.

The other organisms recovered were mainly bacteria which are commonly found on skin. This likely indicates that contamination occurred during the manual handling that was required during the sampling process. It was not possible to conduct this sampling under sterile conditions.

\section{Discussion}

We feel that this system provides a relatively simple, effective and practical approach to the disinfection of some types of anaesthetic equipment. We do not feel that it offers a total solution to the disinfection problem, any more than any other single method does. Its principal use would appear to be in the processing of detachable components of anaesthetic breathing circuits, such as the corrugated breathing tubes, mask connectors, and breathing bags. Because of their size, these items make up the majority of the total mass of equipment which must be processed.

The bacteriological challenge presented by our artificial contamination process was a massive one. This was done deliberately, since we already had the information that clinically contaminated equipment showed no evidence of residual contamination after processing. The massive contamination was well in excess of that which would be encountered in anaesthetic circuits following clinical use. The marked reduction of counts from more than $10^{8}$ organisms per $\mathrm{ml}$ to less than 1 per $40 \mathrm{ml}$ after processing is, we suggest, evidence in support of the process rather than against it.

Some comment is required because of the fact that we have only included four micro-organisms in this study. While these organisms are representative of those known to contaminate anaesthetic equipment, we can only predict, without providing confirmatory evidence, that other vegetative organisms would be similarly affected by the pasteurization process. Spore-forming organisms are of course not killed by pasteurization. Mycobacterium tuberculosis is known to be heat sensitive 
and should be killed by the degree and duration of heat exposure in our machine. Although we have not conducted a systematic study, we have noted that the washing process is effective in removing gross soilage, such as blood or mucus, from processed equipment. We have also not directly examined the effect of this heat process on the life of rubber equipment. However, as others have found, ${ }^{5,8}$ we have not observed any obvious effect of this level of heat on the equipment.

We have encountered some difficulties which are worthy of note. The agitator mechanism of a regular clothes washing machine is not ideally suited to this application. Some form of basket arrangement inside the tub, such as is used in the Cidematic ${ }^{\mathrm{TM}}$ unit $^{9}$ would be more desirable. We have found that the metal head strap holders on face masks will produce tears in equipment when processed in the washing machine. We therefore do not process face masks in our machine because of this damage. A basket arrangement would alleviate this problem. Since disinfection is produced by hot water alone, some precaution must be taken to monitor the temperature of the water feeding the machine to assure that it continually meets the minimum requirement.

We process approximately 60 sets of equipment per day over a ten-hour period. Use of this system has allowed us to achieve our goal of supplying each patient with a disinfected breathing circuit. It must be emphasized that pasteurization produces disinfection but not sterilization. As described above, some equipment, such as tracheal tubes, is initially processed in our pasteurization system, but is subsequently sterilized by ethylene oxide.

In those hospitals where the use of other effective methods of disinfection and sterilization already are in effect, the use of pasteurization offers no advantage. However, in many hospitals, methods currently available are either inadequate or facilities are too small to handle anaesthetic equipment in the volume required. In those circumstances, we feel that the use of a system such as we have described warrants consideration.

\section{ACKNOWLEDGMENT}

The advice and encouragement of Doctor Paul Otton, Department of Anaesthesia, Royal Victoria Hospital, McGill University, is gratefully acknowledged.

\section{SUMMARY}

Using a technique of artificial contamination of anaesthetic breathing tubes we have examined the bacteriological efficacy of a mechanized hot water pasteurization process which involves use of an automatic clothes washing machine. Organisms tested were Pseudomonas aeruginosa, Klebsiella pneumoniae, Staphylococcus aureus, and Streptococcus faecalis. Contamination was massive, greater than $10^{8}$ organisms $/ \mathrm{ml}$. Following pasteurization, 88 of 96 breathing tubes showed no growth of the test organisms while recovery of bacteria in the remaining 8 was at the rate of less than 1 organism $/ 40 \mathrm{ml}$. Pasteurization provides a relatively simple and reliable method of disinfecting some types of anaesthetic equipment, in the absence of other more effective methods. 


\section{RÉSUMÉ}

Les auteurs décrivent une technique de désinfection d'équipement d'anesthésie au moyen de pasteurisation.

L'équipement souillé est placé dans une laveuse à linge automatique, et y est soumis à un lavage de 10 minutes suivi d'un cycle de rinçage de cinq minutes. L'eau de lavage est rechauffée jusqu'à $75^{\circ} \mathrm{C}$, au moyen d'un petit chauffe-eau.

Un savon dissolvant des protéines (LUSAN) est ajouté à l'eau de lavage.

Après rinçage l'équipement est suspendu et séché dans une sècheuse à films radiologiques modifiée.

Ce système a été utilisé depuis trois ans par les auteurs qui le disent pratique et efficace, tout en spécifiant que cette méthode ne stérilise pas l'equipement mais le désinfecte.

\section{REFERENCES}

1. Olds, W.W., Kisch, A.L., Eberle, B.J., \& Wilson, J.N. Pseudomonas aeruginosa respiratory tract infection acquired from a contaminated anesthesia machine. Amer. Rev. Resp. Dis. 105: 628-632 (1972).

2. Tinne, J.E., Gondon, A.M., Bain, W.H., \& MackeY, W.A. Cross-infection by pseudomonas aeruginosa as a hazard of intensive surgery. Brit. Med. J. 4: 313-315 (1967).

3. ERNST, R.R. Ethylene oxide sterilization: I pp. 85-100, In: Infections and sterilization problems. Editor: Roberts, R.B. International Anesthesiology Clinics 10: 2 (1972).

4. Roberts, R.B. Disposables in anesthesiology and respiratory care, pp. 157-177. In: IBID.

5. Roberts, F.J., Cockcroft, W.H., \& Johnston, H.E. A hot water disinfection for inhalation therapy equipment. Canad. Med Assoc. J. 101: 30-32 (1969).

6. Jenkins, J.R.E. \& EDGAR, W.M. Sterilization of anesthetic equipment. Anesthesia 19: $177-190$ (1964).

7. Bahrow, M.E.H. \& MeYneli, M.J. A Method of disinfecting anesthetic equipment. Brit. J. Anesth. 38: 907-910 (1966).

8. BenNetT, P.J., Cope, D.H.P., \& Thompson, R.E.M. Decontamination of anesthetic equipment. A "one-step" washing machine for processing anesthetic equipment and tubing. Anaesthesia 23: 670-675 (1968).

9. STark, D.C.C. Sterilization by chemical agents. pp. 49-65. In: Infection and sterilization problems. Editor: Roberts, R.B. International Anesthesiology Clinics 10: 2 (1972). 